\title{
Y chromosome evidence for a founder effect in Ashkenazi Jews
}

\author{
Almut Nebel ${ }^{1,2,4}$, Dvora Filon ${ }^{2}$, Marina Faerman*,3, Himla Soodyall ${ }^{1}$ and \\ Ariella Oppenheim ${ }^{2}$
}

\begin{abstract}
${ }^{1}$ MRC/NHLS/Wits Human Genomic Diversity and Disease Research Unit, Division of Human Genetics, School of Pathology, National Health Laboratory Service and University of the Witwatersrand, Johannesburg, South Africa; ${ }^{2}$ Department of Hematology, Hebrew University - Hadassah Medical School and Hadassah University Hospital, Jerusalem, Israel; ${ }^{3}$ Laboratory of Biological Anthropology and Ancient DNA, Hebrew University - Hadassah School of Dental Medicine, Jerusalem, Israel
\end{abstract}

Recent genetic studies, based on $\mathrm{Y}$ chromosome polymorphic markers, showed that Ashkenazi Jews are more closely related to other Jewish and Middle Eastern groups than to their host populations in Europe. However, Ashkenazim have an elevated frequency of R-M17, the dominant Y chromosome haplogroup in Eastern Europeans, suggesting possible gene flow. In the present study of $495 \mathrm{Y}$ chromosomes of Ashkenazim, $57(11.5 \%)$ were found to belong to R-M17. Detailed analyses of haplotype structure, diversity and geographic distribution suggest a founder effect for this haplogroup, introduced at an early stage into the evolving Ashkenazi community in Europe. R-M17 chromosomes in Ashkenazim may represent vestiges of the mysterious Khazars.

European Journal of Human Genetics (2005) 13, 388-391. doi:10.1038/sj.ejhg.5201319

Published online 3 November 2004

Keywords: Y chromosome haplotypes; Ashkenazi Jews; founder effect

\section{Introduction}

Ashkenazi Jews, who have resided in various European countries during the Diaspora, traditionally trace their origin to the Jewish people that lived in the Holy Land before the Roman exile. However, some studies claimed that a substantial part of Ashkenazim were descendants of Eastern European non-Jews. In particular, according to Middle Age historians, the Khazars from a small kingdom near the Caspian Sea converted en masse to Judaism ${ }^{1}$ and therefore might have contributed to the composition of

\footnotetext{
*Correspondence: Dr M Faerman, Department of Biological Anthropology and Ancient DNA, Faculty of Dental Medicine, Hebrew University, РОВ 12272, Jerusalem 91120, Israel. Tel: +9722 6757608;

Fax: + 9722 6757451; E-mail: marinaf@pob.huji.ac.il

${ }^{4}$ Current address: Institute for Clinical Molecular Biology - ChristianAlbrechts-University Kiel, Germany

Received 8 January 2004; revised 24 August 2004; accepted 17 September
} 2004 the emerging Ashkenazi community. Yet, recent genetic studies, based on $\mathrm{Y}$ chromosome polymorphic markers, clearly showed that Ashkenazim are more closely related to other Jewish and Middle Eastern groups than to their host populations in Europe. ${ }^{2-4}$ Those findings argue against large-scale male-mediated gene flow into the Ashkenazi community during the Diaspora. The male admixture proportion of Europeans in Ashkenazi Jews was estimated to be $0.5 \%$ per generation, ${ }^{3}$ indicating that Ashkenazim remained, to a large extent, genetically isolated throughout their history.

Ashkenazim were found to have a significantly higher frequency of the R-M17 haplogroup compared with Sephardic and Kurdish Jews. ${ }^{4,5}$ Interestingly, Behar et $a l^{6}$ reported R-M17 to be the dominant haplogroup in Ashkenazi Levites $(\sim 52 \%)$, although rare in Ashkenazi Cohanim (1.3\%) and Israelites (4\%). R-M17, the most common haplogroup in Eastern Europe, was suggested to 
have originated and started to expand in the Ukraine, probably in a Paleolithic population after the Last Glacial Maximum about 13000 years ago. ${ }^{5,7}$

Our present study demonstrates that R-M17 is a distinctive feature of the Ashkenazim in general and not only of Levites, as reported previously. ${ }^{6}$ Furthermore, we provide evidence for a founder effect of this haplogroup in Ashkenazim, dated to the first millennium CE.

\section{Subjects and methods}

A total of 495 DNA samples, from different sources (Table 1), were collected from paternally unrelated male Ashkenazi Jews, irrespective of their religious status (Cohen, Levite, Israelite).

The typing of the Y chromosome biallelic marker M17 and the six microsatelllite loci (DYS19, DYS388, DYS390, DYS391, DYS392 and DYS393) was conducted following Thomas et al. ${ }^{8}$ Statistical analyses were performed as previously described. ${ }^{4}$ The study was approved by the ethics review committees of the respective institutions.

\section{Results and discussion}

In total, 495 DNA samples from different collections (Table 1) were screened for the Y chromosome polymorphism M17. The average frequency of the haplogroup R-M17 in Ashkenazi Jews (11.5\%, 57 individuals) is significantly higher $(P<0.05)$ than that in Sephardic Jews $(3.9 \%)$, Kurdish Jews (4\%) and Palestinian Arabs (1.4\%). To date, comparable frequencies of R-M17 in other Middle Eastern populations have been reported in Moslem Kurds, Syrians and Lebanese (Table 2). However, the haplotype distribution within R-M17, available only for Moslem Kurds, is

Table 1 Frequencies of haplogroup R-M17 in Ashkenazi Jews sampled from various DNA collections

\begin{tabular}{lccc}
\hline Collection & $\begin{array}{c}\text { Sample } \\
\text { size }\end{array}$ & $\begin{array}{c}\text { Number of } \\
\text { chromosomes }\end{array}$ & $\begin{array}{c}\text { Frequency } \\
\text { (\%) }\end{array}$ \\
\hline A & 79 & 10 & 12.7 \\
B & 46 & 4 & 8.7 \\
C & 156 & 19 & 12.2 \\
D & 44 & 4 & 9.0 \\
E & 62 & 7 & 11.3 \\
F & 20 & 3 & 15.0 \\
G & 88 & 10 & 11.3 \\
Total & 495 & 57 & 11.5 \\
\hline
\end{tabular}

Note: collection A - previous study ${ }^{4}$; B - Metabolic Disease Research Unit, Shaarei Zedek Medical Center, Jerusalem; C - Department of Endocrinology, Hadassah Medical Center, Jerusalem; D, E and F Department of Hematology, Hadassah Medical Center, Jerusalem (studies of leukemias and lymphomas, thalassemias, blood clotting disorders); G -MRC/NHLS/Wits Human Genomic Diversity and Disease Research Unit, University of the Witwatersrand, Johannesburg.
Table 2 Haplogroup R-M17 frequencies in Middle Eastern and European populations

\begin{tabular}{|c|c|c|c|}
\hline Population & $\begin{array}{l}\text { Number of } \\
\text { chromosomes }\end{array}$ & $\begin{array}{c}R-M 17 \text { frequency } \\
(\%)\end{array}$ & Reference \\
\hline \multicolumn{4}{|l|}{ Jews } \\
\hline Ashkenazi Jews & 495 & 11.5 & This study \\
\hline Ashkenazi Jews & 82 & 9.7 & 5 \\
\hline Sephardic Jews & 78 & 3.9 & 4 \\
\hline Sephardic Jews & 85 & 3.5 & 5 \\
\hline Kurdish Jews & 99 & 4.0 & 4 \\
\hline \multicolumn{4}{|l|}{ Middle Easterners } \\
\hline Moslem Kurds & 95 & 11.6 & 4 \\
\hline Palestinians & 143 & 1.4 & 4 \\
\hline Lebanese & 31 & 10.0 & 7 \\
\hline Syrians & 20 & 9.7 & 7 \\
\hline \multicolumn{4}{|l|}{ Europeans } \\
\hline North Caucasians ${ }^{a}$ & 140 & 2.9 & 21 \\
\hline Russians & 49 & 43.0 & 22 \\
\hline Ukrainians & 82 & 50.0 & 5 \\
\hline Byelorussians & 306 & 51.0 & 6 \\
\hline Poles & 97 & 59.7 & 5 \\
\hline Hungarians & 49 & 59.1 & 5 \\
\hline Czech and Slovaks & 88 & 32.9 & 5 \\
\hline Lithuanians & 37 & 35.1 & 13 \\
\hline Germans & 88 & 12.5 & 6 \\
\hline Dutch & 27 & 3.7 & 7 \\
\hline French & 23 & 0 & 7 \\
\hline
\end{tabular}

apooled sample comprising five North Caucasian populations.

very different from that of Ashkenazim. ${ }^{4}$ These data suggest that the increase in R-M17 in Ashkenazim occurred after they had gone into the Diaspora.

Variation within R-M17 was examined by analysing 56 of the 57 chromosomes for six microsatellite loci. Apart from one singleton (haplotype H9), the other 13 haplotypes form a compact network (Figure 1). The star-like pattern and the low level of diversity are indicative of a founder effect. The most common R-M17 haplotype in the total Ashkenazi sample ( $\sim 45 \%)$, haplotype 6 (H6), is most likely the ancestral haplotype of this haplogroup among Ashkenazim. The time to the most recent common ancestor of RM17 in Ashkenazim ${ }^{9}$ was estimated to 62.7 generations ago (excluding H9), using the previously published mutation rate for the six microsatellite loci studied here $\left(\mu=1.8 \times 10^{-3}\right.$ with $95 \%$ CI $\left.9.8 \times 10^{-4}-3.1 \times 10^{-3}\right) .{ }^{10}$ Assuming a generation time of 25 years, this amounts to 1567 years ago (95\% CI 2877-910 years ago).

If R-M17 had been present in substantial frequency in the pre-Diaspora Y chromosome pool, one would expect to observe the ancestral haplotype $\mathrm{H} 6$ in other Jewish groups and in Palestinians who share a large portion of their $\mathrm{Y}$ chromosomes with Jews., ${ }^{3,11}$ However, in a combined non-Ashkenazi sample of 320 individuals (Sephardic, Kurdish Jews and Palestinians), ${ }^{4} \mathrm{H} 6$ was found only in a single Sephardic Jew (0.3\%; Figure 1). This finding strongly 


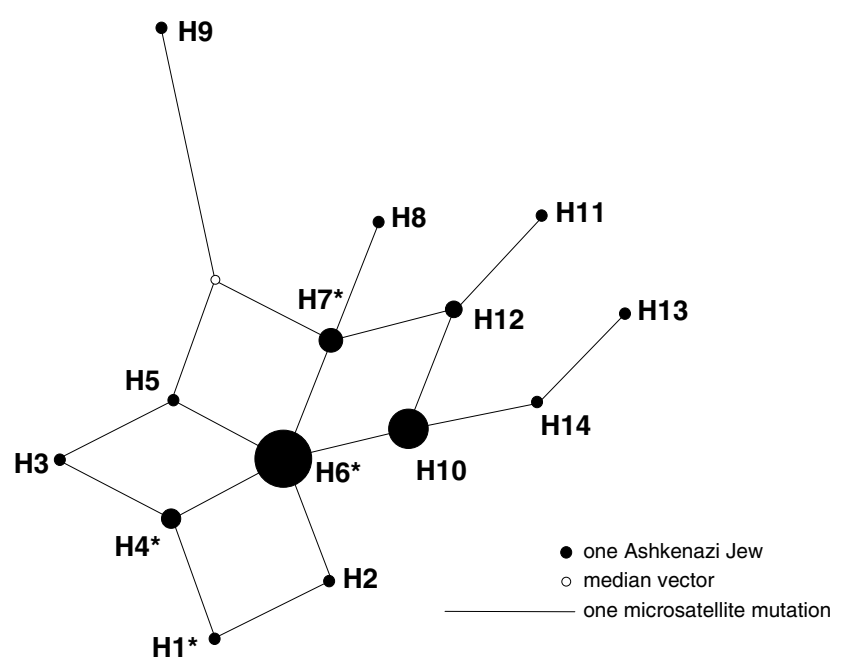

Figure 1 MJ network of haplogroup R-M17 in Ashkenazim. The network shows the relationships of the 14 haplotypes (56 individuals) found in Ashkenazi Jews. Haplotypes were constructed on the basis of six microsatellite loci (DYS19, DYS388, DYS390, DYS391, DYS392 and DYS393). The MJ $(\varepsilon=0)$ was calculated on the data preprocessed by the RM algorithm $(r=2)$. Circle size is proportional to haplotype frequency. Haplotype numbers refer to the supplementary information. At the centre of the network is $\mathrm{H6}$ (16-12-25-10-11-13), the likely founding haplotype of this haplogroup in Ashkenazim. Those haplotypes marked with an asterisk were also observed in other Jewish groups and Moslem Palestinians ${ }^{4}$ ( $\mathrm{H} 6$ and $\mathrm{H7}$ - one Sephardic Jew each; H4 - one Moslem Palestinian; H1 - two Kurdish Jews and one Sephardic Jew).

suggests gene flow from an external population into the Ashkenazi gene pool.

Where did the R-M17 chromosomes in Ashkenazim come from? The haplogroup R-M17 has a wide geographic distribution in Europe, West Asia and the Middle East, with the highest frequencies in Eastern European populations (Table 2). Haplotype $\mathrm{H} 6$ is also present at considerable frequencies in various Eastern European populations, 5,12,13 but is absent or found only at very low frequencies in Central and West Asians and in Middle Easterners. ${ }^{14,15}$ Thus, R-M17 in Ashkenazi Jews could represent gene flow from Eastern European populations. This scenario is supported by the lower haplotype diversity measures $(h)$ in Ashkenazim $(0.735 \pm 0.05)$ compared to those of Eastern European populations $^{5}$ (ranging from $0.894 \pm 0.022$ to $0.919 \pm 0.026)$, and by the fact that in a combined Ashkenazi-European network, Jews present only a subset of the haplotypes (not shown).

The widespread distribution of R-M17 in Europe might suggest multiple gene flow events from the European host populations into Ashkenazim. However, we observed that the frequencies of R-M17 in Jews from various countries (Germany, Lithuania, Czechoslovakia, Hungary, Romania,
Poland, Russia and the Ukraine) ranged from $12-13 \%$ in Russia and Ukraine to $22 \%$ in Germany and Lithuania, and did not differ from one another $(P>0.05)$. Likewise, the haplotypes of Jews from these countries showed very similar distribution patterns in a network (not shown). Furthermore, the frequencies of R-M17 in different Ashkenazi communities did not correspond to the east-west cline seen in Europeans. Altogether, these results support the hypothesis of a single male founder who introduced RM17 into the Ashkenazi gene pool at the beginning of the Jewish Diaspora in Europe. Since then this haplogroup has expanded and spread among the Jewish communities across Europe.

Noteworthy, Behar et al, ${ }^{6}$ in their sample of Ashkenazi Levites, found R-M17 at a frequency of 52\% and its modal haplotype (identical to $\mathrm{H} 6$ in the present study) at $74 \%$ within this haplogroup. They suggested a founder event specific to this particular group as a result of intrusion of one or a few European Y chromosomes into the forming Ashkenazi community. The present study does not necessarily contradict that of Behar et $a l^{6}{ }^{6}$ but rather indicates that R-M17 is characteristic of the general Ashkenazi population and not restricted to the Levites. The proportion of Levites in different Jewish populations has been estimated to range from $0.25^{16}$ to $3.4 \% .^{17}$ Thus, their contribution to the overall frequency of R-M17 in Ashkenazim could not exceed $2 \%$, while the frequency observed in the present study is $11.5 \%$. Similar frequency $(9.7 \%)$ was also reported by Passarino et al. ${ }^{5}$ Furthermore, the haplotype diversity in the Ashkenazi Levites $(0.451)^{6}$ is lower than in the sample of Ashkenazi Jews described here, suggesting that R-M17 drifted to high frequency in the Levites more recently than in the general Ashkenazi population.

It is historically well documented that the Khazar King Bulan and his court converted to Judaism at the end of the 8th century CE. ${ }^{1}$ The Khazars were originally a Turkic tribe from Central Asia who settled in the northern Caucasus and later spread to southern Russia and eastern Ukraine. Some authors argue that after the fall of their kingdom in the second half of the 10th century CE, the Khazar converts were absorbed by the emerging Ashkenazi Jewish community in Eastern Europe. ${ }^{18,19}$ Since R-M17 haplogroup is also found at moderate to high frequencies in Central Asia $^{20}$ and southern Russia/Ukraine, ${ }^{5}$ this haplogroup could have been present in the Khazars. However, if the R-M17 chromosomes in Ashkenazi Jews do indeed represent the vestiges of the mysterious Khazars then, according to our data, this contribution was limited to either a single founder or a few closely related men, and does not exceed $\sim 12 \%$ of the present-day Ashkenazim.

\section{Acknowledgements}

We are grateful to Drs Ben Glaser, Deborah Rund, Avraham Shagg and Ms Ester Hyam for providing DNA samples of Ashkenazim. We 
thank Drs Silvana Santachiara-Benerecetti and Chris Tyler-Smith for sharing haplotype information on European populations. This work was supported by a research grant form the Israeli Ministry of Science, Culture and Sport to $A O$ and MF, and jointly by the Medical Research Council of South Africa, the National Research Foundation, the National Health Laboratory Service and the University of the Witwatersrand to HS. AN was the recipient of the Hillel Friedland Postdoctoral Research Fellowship from the University of the Witwatersrand.

\section{References}

1 Dunlop D: The history of the Jewish Khazars. Princeton: Princeton University Press, 1954.

2 Santachiara-Benerecetti SA, Semino O, Passarino G et al: The common Near Eastern origin of Ashkenazi and Sephardi Jews supported by Y-chromosome similarity. Ann Hum Genet 1993; 57: $55-64$.

3 Hammer MF, Redd AJ, Wood ET et al: Jewish and Middle Eastern non-Jewish populations share a common pool of Ychromosome biallelic haplotypes. Proc Natl Acad Sci USA 2000; 97: 6769-6774.

4 Nebel A, Filon D, Brinkmann B, Majumder PP, Faerman M, Oppenheim A: The Y chromosome pool of Jews as part of the genetic landscape of the Middle East. Am J Hum Genet 2001; 69: $1095-1112$.

5 Passarino G, Semino O, Magri C et al: The 49a,f haplotype 11 is a new marker of the Eu19 lineage that traces migrations from the northern regions of the Black Sea. Hum Immunol 2001; 62: $922-932$.

6 Behar DM, Thomas MG, Skorecki K et al: Multiple origins of Ashkenazi levites: Y chromosome evidence for both Near Eastern and European ancestries. Am J Hum Genet 2003; 73: $768-779$.

7 Semino O, Passarino G, Oefner PJ et al: The genetic legacy of Paleolithic Homo sapiens sapiens in extant Europeans: a Y chromosome perspective. Science 2000; 290: 1155-1159.

8 Thomas MG, Bradman N, Flinn H: High throughput analysis of 10 microsatellite and 11 diallelic polymorphisms on the human $\mathrm{Y}$ chromosome. Hum Genet 1999; 105: 577-581.

9 Kittles RA, Perola M, Peltonen L et al: Dual origins of Finns revealed by Y chromosome haplotype variation. Am J Hum Genet 1998; 62: 1171-1179.
10 Quintana-Murci L, Krausz C, Zerjal T et al: Y chromosome lineages trace diffusion of people and languages in southwestern Asia. Am J Hum Genet 2001; 68: 537-542.

11 Nebel A, Filon D, Weiss D et al: High-resolution Y chromosome haplotypes of Israeli and Palestinian Arabs reveal geographic substructure and substantial overlap with haploytpes of Jews. Hum Genet 2000; 107: 630-641.

12 Zerjal T, Pandya A, Santos FR et al: The use of Y-chromosomal DNA variation to investigate population history: recent male spread in Asia and Europe; In Papiha SS, Deka R, Chakraborty R (eds): Genomic diversity: applications in human population genetics. New York: Plenum Press, 1999, pp 91-101.

13 Zerjal T, Beckman L, Beckman G et al: Geographical, linguistic, and cultural influences on genetic diversity: Y-chromosomal distribution in Northern European populations. Mol Biol Evol 2001; 18: 1077-1087.

14 Zerjal T, Wells RS, Yuldasheva N, Ruzibakiev R, Tyler-Smith C: A genetic landscape reshaped by recent events: Y-chromosomal insights into central Asia. Am J Hum Genet 2002; 71: $466-482$.

15 Weale ME, Yepiskoposyan L, Jager RF et al: Armenian Y chromosome haplotypes reveal strong regional structure within a single ethno-national group. Hum Genet 2001; 109: 659-674.

16 Kosmin BA, Waterman S: The use and misuse of distinctive Jewish names; In Schmelz UO, Della Pergola S (eds): Papers in Jewish Demography 1985. Jerusalem: The Hebrew University of Jerusalem, 1989, pp 1-10.

17 Della Pergola S: Alcuni aspetti quantitativi della distribuzione del cognome fra gli ebrei in Italia. Annu Studi Ebraici 1984, vol. 10. Rome, Carucci, pp 65-86.

18 Brook KA: The Jews of Khazaria. Northvale, NJ: Jason Aronson, 2002.

19 Koestler A: The thirteenth tribe: the Khazar Empire and its heritage. New York, NY: Random House Trade Paperbacks, 1976.

20 Underhill PA, Jin L, Lin AA et al: Detection of numerous Y chromosome biallelic polymorphisms by denaturing highperformance liquid chromatography. Genome Res 1997; 7: 996-1005.

21 Nasidze I, Sarkisian T, Kerimov A, Stoneking M: Testing hypotheses of language replacement in the Caucasus: evidence from the Y chromosome. Hum Genet 2003; 112: 255-261.

22 Wells RS, Yuldasheva N, Ruzibakiev R et al: The Eurasian heartland: a continental perspective on Y-chromosome diversity. Proc Natl Acad Sci USA 2001; 98: 10244-10249. 